\title{
Rozwój techniki komputerowego przetwarzania obrazów w AGH
}

\section{Development of computer vision techniques at AGH University of Science and Technology}

\section{Streszczenie}

Przedstawiono historię rozwoju badań związanych z komputerowym przetwarzaniem, analizą i rozpoznawaniem obrazów. Opisano, jak w latach 70 . XX w. pracownicy AGH własnoręcznie budowali zarówno przetworniki wprowadzające pierwsze obrazy do komputerów, jak i procesory przetwarzające te obrazy. Wzmiankowano o pierwszych systemach wieloprocesorowych do przetwarzania obrazów, które zbudowano na AGH w latach 80. korzystając z układów scalonych małej i średniej skali integracji oraz z systemów realizowanych głównie $z$ wykorzystaniem zaawansowanych technik oprogramowania przy niewielkim wkładzie sprzętowego przetwarzania obrazów.

W artykule omówiono także poszukiwania zastosowań tych systemów w połączeniu z technikami opartymi na sieciach neuronowych na początku lat 90 . Obecnie wszystkie te dokonania i związane z nimi, przywołane w artykule publikacje, mają wyłącznie historyczne znaczenie, ponieważ współczesne systemy oparte są głównie na rozwiązaniach czasu rzeczywistego opartych na technologii FPGA. Czasem warto jednak odwołać się do historii, żeby lepiej rozumieć dzień dzisiejszy określonej dziedziny oraz trafniej przewidywać kierunki jej rozwoju.

\section{Abstract}

In the paper is presented the brief history of research conducted at AGH University of Science and Technology in the area of image processing, analysis and recognition. The history is connected with changes of the technology used for problem solving. First systems are build from the separate integrated circuits of low and medium scale of integration, after this we develop some systems build on the base of VLSI elements, and now the new systems are constructed on the base of FPGA technology. Nevertheless all the time scientific group from AGH was conducted research in technological applications of vision systems. At 70 th and 80th years of XX century it was pioneer works devoted to building of second in Poland and one of the first in Europe systems for computer processing of the images.

Now the problems mentioned can be find as fully solved, but the new challenging goals occur and new research is conducted toward to most and most ambitions technological applications of computer vision systems. In the paper was described way from the very beginning computer vision systems produced in AGH laboratories, next the development of such system is described and actual state of art is presented.

\section{Wstęp}

Problematyka cyfrowego przetwarzania obrazów stała się techniką bardzo popularną i powszechnie wykorzystywaną. Wystarczy wspomnieć tylko o wszechobecnych cyfrowych aparatach fotograficznych oraz o cyfrowych kamerach wideo, które tak dalece zostały udoskonalone technicznie oraz dopracowane pod względem ekonomicznego wytwarzania, że są nawet rutynowo wbudowywane jako swoisty bonus do telefonów komórkowych. Cyfrowe obrazy towarzyszą nam także stale przy różnych formach komunikacji multimedialnej oraz stanowią coraz większą część zawartości różnych zasobów informacyjnych - na przykład Internetu, więc dla dzisiejszego użytkownika komputerów operowanie obrazem jest czymś oczywistym i naturalnym (por. [1]).

Warto jednak uświadomić sobie, że nie zawsze tak było! Technika cyfrowa została stworzona pierwotnie po to, by operować na liczbach, a nie na obrazach, zaś komputer - także zgodnie ze swoją nazwą - jest narzędziem do prowadzenia obliczeń, a nie do określania deformacji wątroby na ultraso-

Prof. dr hab. inż. Ryszard Tadeusiewicz - Akademia Górniczo-Hutnicza. nogramie. To, że dzisiaj z taką swobodą korzystamy z technik cyfrowego przetwarzania i rozpoznawania obrazów - jest wynikiem wieloletniego procesu rozwijania i doskonalenia tych technik, a w tym historycznym procesie pracownicy AGH mieli swój udział. W artykule tym chciałbym przypomnieć niektóre osiągnięcia, jakie w tym zakresie udało się uzyskać, pokazując, jak długą i trudną drogą dążyliśmy do naszego obecnego poziomu kompetencji, związanego z metodami określanymi często angielskim terminem computer vision.

Publikując prace dotyczące komputerowego przetwarzania obrazów, odwołujemy się do najnowszych osiągnięć, jakie udało się w tym zakresie uzyskać, jednak w tym artykule, na zasadzie wyjątku od reguły, celowe będzie sięgnięcie do przeszłości (patrz na przykład $[2 \div 4]$ ). Spróbuję więc przedstawić, jak wyglądały początki rozwoju problematyki komputerowego przetwarzania obrazów w AGH w „pionierskim” okresie rozwoju tej techniki, gdy naprawdę mało kto wiedział, o co właściwie chodzi w przetwarzaniu obrazów, a wiele autorytetów wypowiadało bardzo stanowcze opinie, że do takich celów komputerów się nie powinno stosować, bo nie takie jest ich przeznaczenie.

Akademia Górniczo-Hutnicza jest uczelnią techniczną, dlatego rozwijając metody przetwarzania obrazów w tej uczelni zawsze stawiano na pierwszym planie potrzeby przemysłu, 
a zwłaszcza tych jego dziedzin, które związane są z górnictwem i hutnictwem. Warto wspomnieć, że pierwszy system wizyjny zbudowany w AGH służył do sterowania procesem wzbogacania surowców mineralnych, a konkretnie technologią flotacji rud miedzi, cynku i ołowiu w oparciu o obraz piany flotacyjnej obserwowany przez przemysłową kamerę i przetwarzany przez komputer przystosowany do pracy w warunkach przemysłowych. Dalsze prace zmierzały do zaopatrzenia w wizyjne sprzężenie zwrotne robotów przemysłowych wykonujących proste prace inspekcyjne, montażowe (w tym także spawalnicze) oraz związane z sortowaniem obiektów.

\section{Problem wprowadzania obrazu do komputera}

Z punktu widzenia dzisiejszego użytkownika wszechobecnych i bardzo sprawnych urządzeń, pozwalających szybko i wygodnie pozyskiwać cyfrowe obrazy i wprowadzać je do komputerów, trudno sobie wyobrazić, jak wielki był to kiedyś problem. Gdy zaczynano w AGH badania nad technikami automatycznego przetwarzania i analizy obrazów, podstawowym sposobem wprowadzania informacji do komputera były taśmy oraz karty dziurkowane (rys. 1).

Trzeba było najpierw opracować, a potem własnoręcznie zbudować i przetestować urządzenia elektroniczne. Pierwsze (jak się wydaje) prace poświęcone rozważanej problematyce powstały w połowie lat 70 . ub.w. i zaowocowały całym szere-

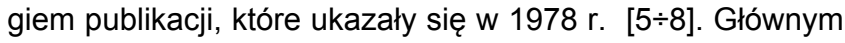
źródłem kłopotów był w tym czasie przetwornik pozwalający wprowadzić do powolnych ówczesnych komputerów obrazy dostarczane z dużą szybkością przez typowe (analogowe) kamery telewizyjne. Zbudowanie takiego przetwornika przy zastosowaniu układów elektronicznych dostępnych w latach 70. było bardzo trudne, strumień informacji cyfrowej, który był produkowany przez taki przetwornik, był za duży i za szybki jak na możliwości ówczesnych komputerów. Konieczne więc było stosowanie pamięci buforowych przechwytujących cyfrowy obraz - oczywiście pamięci także własnoręcznie budowanych z układów elektronicznych o bardzo małej skali integracji (rys. 2).

Mając jednak nakreślony cel, jakim była automatyzacja procesu wzbogacania surowców w górnictwie oraz mając (dzięki współpracy z KGHM) praktycznie nieograniczone środki finansowe, $z$ tytułu priorytetowego finansowania $w$ po-

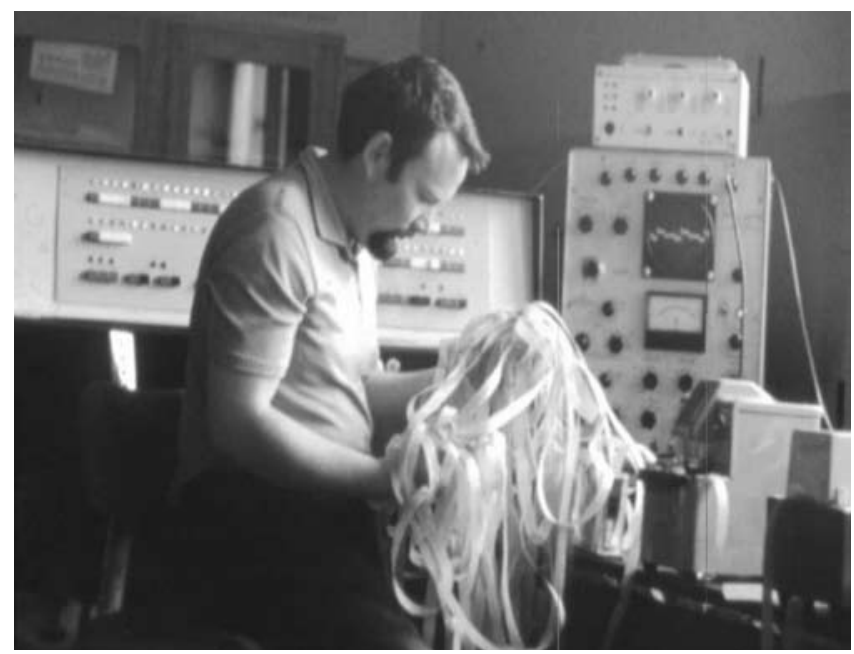

Rys. 1. Dawne metody wprowadzania informacji do komputerów nie sprzyjały technice przetwarzania obrazów

Fig. 1. Former methods of computer data entry did not support image processing technologies

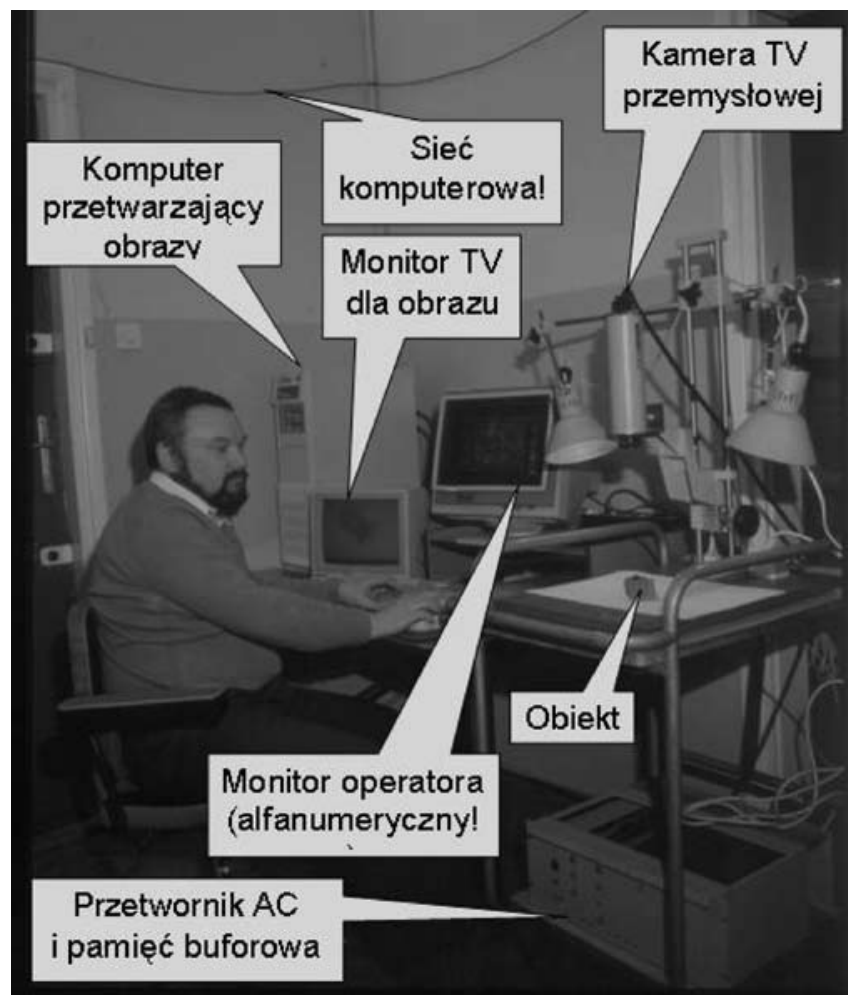

Rys. 2. Skonstruowany w AGH pierwszy cyfrowy system wizyjny CESARO

Fig. 2. The first CESARO digital imaging system designed by AGH [University of Mining and Metallurgy]

łowie lat 70. prac badawczych dotyczących górnictwa, zbudowaliśmy system komputerowego przetwarzania obrazów, nazwany CESARO (Cyfrowy Eksperymentalny System Analizy i Rozpoznawania Obrazów).

Był to wtedy drugi w Polsce i jeden z pierwszych w Europie systemów tego typu. CESARO był wielokrotnie opisywany w literaturze $[9 \div 10]$ oraz stał się od razu bazą do prowadzenia szeregu różnych badań w dziedzinie komputerowej

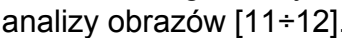

Warto podkreślić, że w pracach związanych z budową i oprogramowaniem pierwszych polskich systemów wizyjnych nie brakowało różnych trudności i kłopotów, o których współcześnie pracujący badacze computer vision nie mają pojęcia, że mogły kiedykolwiek występować. Obraz nie tylko trudno było wprowadzić do komputera, ale także bardzo trudno było go obejrzeć, gdy już tkwił w pamięci maszyny - na przykład po wykonaniu jakiejś operacji wchodzącej w skład jego przetwarzania oraz analizy. Dzisiaj trudno to sobie wyobrazić, ale używane w tamtych czasach monitory i drukarki nie miały możliwości wyświetlania czy drukowania obrazów, gdyż były to urządzenia w ścisłym tego słowa znaczeniu alfanumeryczne.

Z wyświetleniem obrazu można sobie było poradzić w taki sposób, że do komputera dołączano (poprzez przetwornik cyfrowo-analogowy) typowy monitor studyjny (używany $\mathrm{w}$ studio telewizyjnym do podglądania emitowanego programu). Stosowne oprogramowanie komputera skanowało jego pamięć, w której zawarty był interesujący nas obraz (na przykład będący wynikiem procesu przetwarzania) i wysyłało sygnały sterujące praca przetwornika wyświetlającego obraz na ekranie. Było z tym oczywiście sporo kłopotów w szczegółach (na przykład problem synchronizacji komputera z monitorem), ale dawało się to rozwiązać.

Prawdziwy problem pojawiał się w momencie, gdy trzeba było uzyskać trwałą kopię przetwarzanego albo analizowanego cyfrowego obrazu. W odróżnieniu od monitora, którego elektroniczna konstrukcja była w miarę przyjazna dla wszel- 

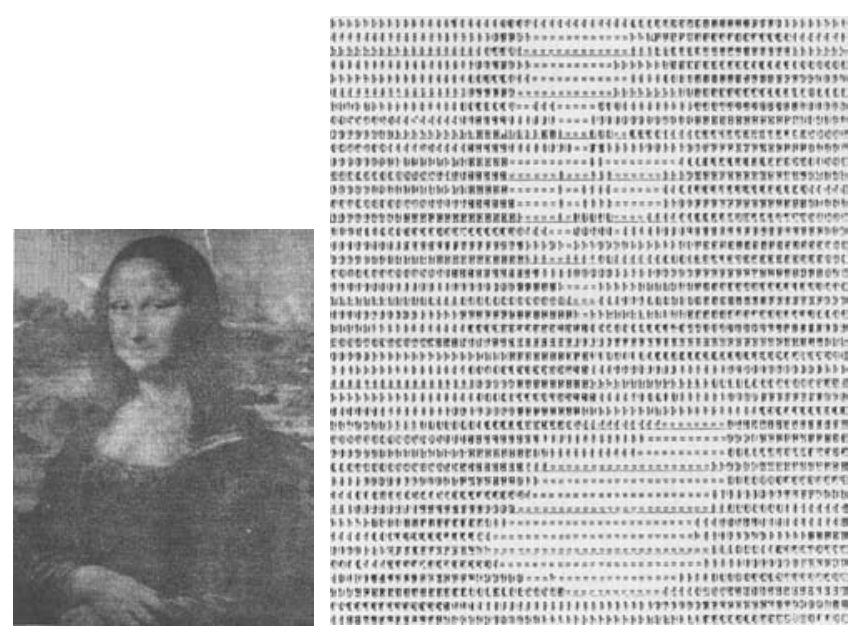

Rys. 3. Sposób przedstawiania obrazu cyfrowego z wykorzystaniem drukarki alfanumerycznej

Fig. 3. Method of digital image presentation using an alphanumeric printer

kich przeróbek, drukarki zawierały całą masę nieodzownych elementów mechanicznych, których wykonanie albo przeróbka w warunkach AGH były bardzo utrudnione. Mechanika precyzyjna (a raczej jej brak...) jest zreszta do dzisiaj czynnikiem limitującym możliwości uczelni w wielu ciekawych obszarach badawczych - na przykład mikrorobotów.

Wracając do problemu drukowania obrazów - okazało się, że jedyną szansą uzyskania „obrazopodobnego" zapisu na papierze jest technika nabijania na siebie znaków drukarskich w taki sposób, żeby łączny stopień zaczernienia papieru osiągnął pożądaną wartość. Na rysunku 3 pokazano przykładowy wydruk obrazu uzyskany tą metodą. Nie została żadna próbka alfanumerycznie generowanych obrazów naukowych, natomiast udało się znaleźć przedstawiony przykład takiego wydruku innego (znanego) obrazu.

\section{Badania związane z przetwarzaniem obrazów}

Ze względu na swoją unikatowość pod względem obszaru zastosowań (używano go m.in. do optymalizacji flotacji rud miedzi) CESARO był podstawą opracowań technologicznych, które były dosyć szeroko komentowane w środowisku specjalistów związanych z przeróbką surowców mineralnych $[10,13,14]$. Po kilku latach doświadczeń z eksploatacją (stale rozbudowywanego) systemu CESARO, a także z projektowaniem nowych algorytmów przetwarzania obrazów oraz z programowaniem ich w sposób zapewniający dużą szybkość przetwarzania mimo ogromnego rozmiaru zbioru danych, jaki w systemie informatycznym reprezentuje każdy obraz - udało się w 1982 r. przedstawić pierwsze w Polsce obszerne opracowanie metodologiczne, opisujące możliwości i ograniczenia technik obrazowych, będących wtedy wciąż jeszcze mało znaną nowością [15].

Popularna wersja tego opracowania, opublikowana w czasopiśmie Informatyka [16] była przez kilka następnych lat źródłem inspiracji do wielu prób budowy systemów wizyjnych w różnych ośrodkach naukowych na terenie całej Polski (potwierdzają to cytowania wskazanego artykułu w pracach innych badaczy).

Zaletą systemu CESARO był wysoki poziom zaawansowania technicznego (oczywiście w stosunku do stanu nauki i techniki w czasach, w których powstał i był rozwijany). Był on $w$ całości budowany $z$ łatwo dostępnych i relatywnie tanich elementów krajowych. Dzisiejszym badaczom kryterium takie wydaje się zapewne dziwaczne i bezsensowne, bo do budowy określonego stanowiska badawczego staramy się dobierać elementy według ich jakości („tylko najlepsze są wystarczająco dobre"), a nie według kryterium kraju produkcji. Rynek stał się rynkiem globalnym. W latach 80 . było jednak inaczej. Elementy i podzespoły pochodzące z importu były trudno osiągalne (czasem całkowicie nieosiągalne), a całkowicie „sufitowe" relacje kursów walut powodowały, że nawet najtańsze elementy pochodzące z Zachodu były znacznie droższe od takich samych wyprodukowanych w ramach Bloku Wschodniego. Dlatego prezentując system CESARO na różnych konferencjach, eksponowano jego konstrukcję opartą na podzespołach krajowych, bo to wtedy miało istotne znaczenie, zwłaszcza że porównanie możliwości funkcjonalnych i sprawności działania naszego systemu ze znanymi z literatury systemami innych badaczy dawało raczej zachęcające wyniki $[17 \div 18]$.

Zbudowawszy system CESARO, nie poprzestaliśmy na samym tylko jego uruchomieniu i zastosowaniu do różnych zagadnień praktycznych. Poszukiwaliśmy także metod pozwalających na zwiększenie szybkości przetwarzania obrazów metodą wykorzystania faktu, że w spakowanej postaci obraz był rozmieszczony w pamięci komputera w taki sposób, że w jednej komórce pamięci mieściło się kilka pikseli [19]. W tamtych czasach struktura bajtowa nie była jedyna stosowaną, jak to ma miejsce dzisiaj, i używano także pojęcia komórki pamięci jako jednostki przetwarzanej w jednym cyklu pracy procesora. Ta nieco egzotyczna z dzisiejszego punktu widzenia technika przyspieszania obliczeń okazywała się niekiedy nadspodziewanie skuteczna, co pozwalało na wzrost wydajności przetwarzania bez konieczności sięgania do architektur wieloprocesorowych. Kolejne korzyści w zakresie oprogramowania naszego systemu wizyjnego udało się osiągnąć, wprowadzając nową i oryginalną architekturę oprogramowania wykorzystującą hierarchiczne zależności między operacjami wykonywanymi na obrazie przy różnym poziomie szczegółowości jego opisu [20]. Te pomysły mogą budzić zainteresowanie jedynie jako ciekawostki, kiedyś jednak była to realna i ważna droga uzyskiwania zwiększonej wydajności procesu przetwarzania przy bardzo powolnych dostępnych wtedy komputerach.

Zbudowany system wizyjny zachęcał do prowadzenia badań nad różnymi obszarami jego zastosowań. Ponieważ prace prowadzone były głównie w Katedrze Automatyki AGH - obszarem pierwszych zastosowań stały się oczywiście zastosowania w automatyce [21] (na przykład w procesie ciągnienia szkła okiennego w hucie [22]), potem przyszła pora

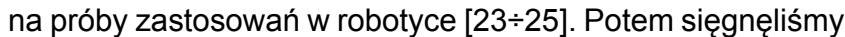
do zastosowań telekomunikacyjnych [26] oraz medycznych [27], które na długo stały się głównym wątkiem rozwijanych w AGH prac.

\section{Systemy wieloprocesorowe CESARO2}

Coraz poważniejsze zadania, powierzane systemom przetwarzania obrazów, spowodowały, że mający już 10 lat system CESARO, mimo jego modyfikacji i stałego doskonalenia, przestał spełniać wymagania. W związku z tym pod koniec lat 80. przystąpiono w Katedrze Automatyki AGH do budowy systemu CESARO2, którego cechą wyróżniającą była wieloprocesorowość $[28,29]$. Nowy system w dużej mierze oparty był na przesłankach biocybernetycznych i wykorzystywał rozwijaną w AGH od wielu wcześniejszych lat teorię i praktykę systemów neuropodobnych [30]. Dzięki popularyzacji idei budowy wieloprocesorowego systemu wizyjnego dla 
potrzeb robotyki [31] udało się zdobyć potrzebne środki i wieloprocesorowy system wizyjny CESARO2 został zbudowany (rys. 4). System ten był wykorzystywany eksperymentalnie jako wizyjne sprzężenie zwrotne dla robota przemysłowego typu IRb6 (ASEA-PIAP), co stało się podstawą do napisania książki „Systemy wizyjne robotów przemysłowych” [32], będącej pierwszą polską ogólnie dostępną monografią, w której przedstawiono zasady komputerowej analizy, przetwarzania i rozpoznawania obrazów wraz z ich praktyczną realizacją w postaci specjalizowanych układów elektronicznych. Wydana rok wcześniej książka „Rozpoznawanie obrazów” koncentrowała się bowiem na podejściach teoretycznych i algorytmicznych [33]. Bogate możliwości prowadzenia z użyciem systemu CESARO2 badań różnych metod przetwarzania i rozpoznawania obrazów skierowały na początku lat 90 . uwagę badaczy z AGH na możliwości, jakie w tym zakresie dawała technika sieci neuronowych, które właśnie w tym czasie zaczęły zyskiwać rosnącą popularność. Powstała wtedy praca [34] stanowiła pierwszy polski przegląd możliwości, jakie w tym zakresie dają się wskazać, zaś kolejna praca [35] proponowała konkretną metodologię wiązania techniki komputerowej analizy i przetwarzania obrazów z metodami i technikami sieci neuronowych. Rozwijanie tej idei i tej drogi postępowania doprowadziło do powstania w całej Polsce przynajmniej kilkunastu bardzo ciekawych prac doktorskich, bowiem połączenie techniki przetwarzania obrazów i sieci neuronowych okazało się wyjątkowo użytecznym narzędziem w niespodziewanie szerokim zakresie różnych zagadnień i problemów wynikających z potrzeb praktyki [36, 37]. Przykładem dosyć nieoczekiwanego zastosowania połączonych technik obrazowych i neuronowych może być praca [38], pokazująca możliwości tych technik w zagadnieniach technologii żywności. W związku z tą szeroko potwierdzoną użytecznością praktyczną narzędzie będące połączeniem technik obrazowych i sieci neuronowych było także przedmiotem dosyć rozległych badań podstawowych prowadzonych w AGH od 1992 r., a ukoronowanych między innymi publikacją [39].

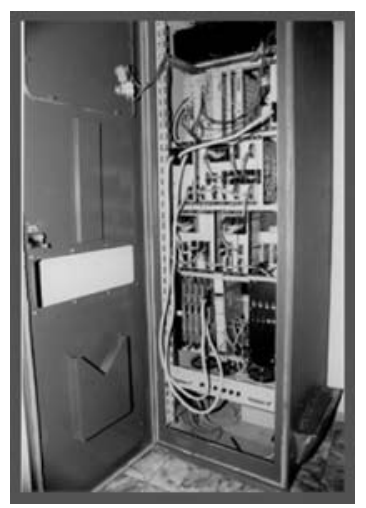

Rys. 4. Wieloprocesorowy system wizyjny CESARO2

Fig. 4. CESARO2 multiple processor imaging system
Z wykorzystaniem systemu CESARO2 wykonywano różne prace, między innymi podjęto jedne z pierwszych w Polsce badania możliwości wykorzystania komputerowego rozpoznawania obrazów do odczytywania tekstów drukowanych i pisanych ręcznie. Wyniki tych prac były podstawą zarówno prac naukowych, jak i serii opracowań popularnych [40, 41], przedstawiających możliwości tej (mało znanej wówczas) techniki szerokiej społeczności polskich informatyków. Badania te później zaowocowały między innymi praktycznym rozwiązaniem wykorzystującym technikę optycznego czytania dokumentów do szybkiego wprowadzania do komputerowego systemu rekrutacyjnego ręcznie wypełnianych ankiet kandydatów na studia w AGH oraz ciekawymi wynikami naukowymi [42].

\section{A potem ruszyła lawina...}

Opis pionierskich prac badawczych i konstrukcyjnych, dotyczących komputerowego przetwarzania obrazów, prowadzonych w AGH od lat 70 . XX wieku, wypada zakończyć na granicy połowy lat 90 . Nie dlatego, żeby później dalszych prac w tej dziedzinie w AGH nie prowadzono. Przeciwnie, w latach 90. oraz na początku XXI stulecia w AGH powstało wiele bardzo ciekawych prac, poświęconych problematyce przetwarzania i rozpoznawania obrazów. Rozpoczęto bardzo zaawansowane badania dotyczące rozpoznawania i rozumienia obrazów medycznych (prof. Marek Ogiela). Podjęto ciekawy temat wideo-detektorów ruchu drogowego, wykorzystywanych przy systemach automatycznego monitoringu i sterowania ruchem drogowym (prof. Andrzej Adamski, dr Zbigniew Mikrut). Prowadzone są prace zmierzające do realizacji coraz większej liczby zadań przypisanych do wizji komputerowej za pomocą specjalizowanych procesorów wykonanych w technologii FPGA (dr Marek Gorgoń). Podjęto i rozwiązano szereg ciekawych zadań związanych z wykorzystaniem techniki przetwarzania obrazów do różnych problemów automatyki przemysłowej (dr Zbigniew Bubliński i dr Piotr Pawlik). Pewien przegląd tych późniejszych prac można znaleźć w publikacjach, a także w podręczniku, który powstał

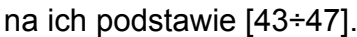

Jednak mimo intensywnego rozwoju problematyki komputerowego przetwarzania, analizy, rozpoznawania i rozumienia obrazów w AGH - dziedzina ta przestała być unikatowym wyróżnikiem.

O przyszłość dyscypliny komputerowej analizy, przetwarzania i rozpoznawania obrazów martwić się nie musimy, bo trudzą się nad nią najlepsze umysły i najsilniejsze ośrodki badawcze w całej Polsce. W związku z tym od czasu do czasu, nie za często, ale na przykład z okazji jubileuszu, warto wspomnieć także o przeszłości tej dziedziny - i to właśnie było celem tego artykułu.

\section{Literatura}

[1] Tadeusiewicz R.: Rola technik cyfrowych w komunikacji społecznej oraz w kulturze i edukacji. W pracy zbiorowej: Handzelewicz M. (red.): Cyfrowy świat bibliotek - problemy techniczne, prawne, wdrożeniowe. CPI Warszawa, 2006.

[2] Tadeusiewicz R., Ogiela M. R.: Intelligent Recognition in Medical Pattern Understanding and Cognitive Analysis. Chapter in book: Muhammad Sarfraz (ed.): Computer-Aided Intelligent Recognition Techniques and Applications, John Wiley \& Sons, Ltd., Hoboken, New Jersey, 2005
[3] Tadeusiewicz R., Ogiela M. R.: Picture Languages in Automatic Radiological Palm Interpretation, International Journal of Applied Mathematics and Computer Science, vol. 15, no. 2, 2005.

[4] Tadeusiewicz R., Ogiela M.R.: New Proposition for Intelligent Systems Design: Artificial Understanding of the Images as the Next Step of Advanced Data Analysis After Automatic Classification and Pattern Recognition. In: Kwasnicka H., Paprzycki M. (eds.): Intelligent Systems Design and Applications, IEEE Computer Society Press, Los Alamitos, Washington, Brussels, Tokyo, 2005. 
[5] Tadeusiewicz R.: Rozpoznawanie obrazów. Informatyka, nr 12, 1978.

[6] Tadeusiewicz R.: Komputerowa analiza przydatności wybranych metod rozpoznawania obrazów w diagnostyce neuroinfekcji. W mat. II Krajowej Konferencji Biocybernetyka i Inżynieria Biomedyczna, Gliwice, 1978.

[7] Tadeusiewicz R.: Cyfrowe przetwarzanie obrazów telewizyjnych w celu ich analizy i rozpoznawania. W mat. IV Symp. MPN WEAE AGH, 1978.

[8] Kordek J., Nipl R., Nowikow P., Romanowski J., Szuba T., Tadeusiewicz R.: Rozpoznawanie obrazów optycznych w przeróbce surowców mineralnych. W mat. Symp.: Automatyzacja Procesów Przeróbki Węgla, Katowice, 1978.

[9] Tadeusiewicz R., Kordek J., Nipl R.: Cyfrowy eksperymentalny system analizy i rozpoznawania obrazów CESARO Zeszyty Naukowe AGH, 1979.

[10] Kordek J., Nipl R., Sztaba K., Tadeusiewicz R.: CESARO - the digital experimental system of analysis and recognition of images. 17-th International Symposium on the Application of Computer and Mathematics in the Mineral Industries, Moskwa, 1980.

[11] Tadeusiewicz R.: Programy analizy składu ziarnowego materiałów sypkich w systemie CESARO. Zeszyty Naukowe AGH, 1979.

[12] Tadeusiewicz R., Mikrut Z.: Komputerowa analiza współczynników kształtu ziaren z wykorzystaniem systemu CESARO. Zeszyty Naukowe AGH, 1979.

[13] Sztaba K., Nipl R., Kordek J., Tadeusiewicz R., Romanowski J., Nowikow P.: Auswertung optischer Aufnahmen bei der Aufbereitung mineralischer Rohstoffe. Physikalische Eigenschaften von Kornmengen und Kornschuttungen, Leipzig, 1980.

[14] J. Kordek, R. Nipl, K. Sztaba, Tadeusiewicz R.: Eksperymentalnaja cifrowaja sistiema CESARO analiza i raspoznawania obrazow. Primienienie EWM i matematiczieskich mietodow w gornom dielie - Trudy 17-go miezdunarodnogo simpozjuma, Moskwa, 1982.

[15] Tadeusiewicz R.: Komputerowa analiza obrazów i jej zastosowania. Elektrotechnika, tom I, zeszyt 21982.

[16] Tadeusiewicz R., Pachowicz P.: CESARO - system analizy i rozpoznawania obrazów wizualnych. Informatyka $\mathrm{nr} 7 / 8,1983$.

[17] Pachowicz P., Tadeusiewicz R.: System CESARO jako propozycja wykorzystania krajowego sprzętu informatycznego do analizy i przetwarzania obrazów. VI Ogólnopolska Konferencja Biocybernetyki i Inżynierii Biomedycznej, Warszawa, 1983.

[18] Pachowicz P., Tadeusiewicz R.: Porównanie systemu CESARO $z$ wybranymi systemami analizy i rozpoznawania obrazów, Elektrotechnika, tom 3, zeszyt 2, 1984.

[19] Pachowicz P., Tadeusiewicz R.: Efektywność zastosowania przetwarzania pół-równoległego $w$ sekwencyjnych systemach obrazowych. I Krajowa Konferencja „Przetwarzanie sygnałów w telekomunikacji, sterowaniu i kontroli”, 1984.

[20] Tadeusiewicz R.: Hierarchiczny system oprogramowania systemu analizy i rozpoznawania obrazów. I Krajowa Konferencja „Przetwarzanie sygnałów w telekomunikacji, sterowaniu i kontroli", 1984.

[21] Pachowicz P., Tadeusiewicz R.: Zadania, metody i zastosowania $w$ automatyzacji procesów produkcyjnych komputerowej analizy obrazów. Zastosowania Komputerów w Przemyśle, Szczecin, 1983.

[22] Skowiniak A., Tadeusiewicz R.: Eine Konzeption des Visionssystems für die Automatisierung der Ziehmaschinen. 14 Glastechnikertagung der DDR, pp. 42-44, Berlin, 1987.

[23] Tadeusiewicz R.: Rola podsystemu wizyjnego w systemie sterowania robota. Prace Naukowe Instytutu Cybernetyki Technicznej PW, nr 75, Wrocław, 1988.

[24] Tadeusiewicz R.: Systemy wizyjne robotów przemysłowych. Materiały III Krajowej Konferencji Naukowo-Technicznej „Przetwarzanie sygnałów w telekomunikacji, sterowaniu i kontroli", Bydgoszcz, 1988.

[25] Tadeusiewicz R.: Systemy wizyjne dla robotów przemysłowych: rola, budowa, zastosowanie, Zeszyty Naukowe AGH nr 1260, Automatyka, nr 47, 1989.
[26] Tadeusiewicz R., Pachowicz P.: CESARO - nowy system automatycznej analizy obrazów. Wiadomości Telekomunikacyjne, nr 5-6, 1984

[27] Tadeusiewicz R.: Metody rozpoznawania obrazów i ich medyczne zastosowania. Jubileuszowy Zjazd Towarzystwa Chirurgów Polskich, Kraków, 1989.

[28] Tadeusiewicz R.: Wieloprocesorowe przetwarzanie obrazów. Szkoła Wizji Komputerowej i Sztucznej Inteligencji, Polska Akademia Nauk, IPPT, Mądralin, 1989.

[29] Tadeusiewicz R.: The Multiprocessor Architectures for Image Processing. Lecture Notes on Computer Vision and Artificial Intelligence, Ossolineum, Wrocław, 1990.

[30] Tadeusiewicz R.: Modele sieci neuropodobnych i przetwarzania informacji w biologicznych systemach percepcyjnych. IV Ogólnopolskie konwersatorium: Cybernetyka - inteligencja-rozwój, PTC, Siedlce, 1989.

[31] Tadeusiewicz R.: Inteligentne oko robota, Sprawy Nauki, nr 5, 1992.

[32] Tadeusiewicz R.: Systemy wizyjne robotów przemysłowych, WNT, Warszawa, 1992.

[33] Tadeusiewicz R., Flasiński M.: Rozpoznawanie obrazów, PWN, Warszawa, 1991.

[34] Tadeusiewicz R.: Sieci neuronowe w rozpoznawaniu obrazów. Mat. konf. „Uniwersalność cybernetyki”, Kraków, 1993.

[35] Mikrut Z., Tadeusiewicz R.: Metodyka eksperymentów z sieciami neuronowymi rozpoznającymi obrazy, Zeszyty Naukowe AGH, „Automatyka”, nr 66, 1993.

[36] Tadeusiewicz R.: Komputerowe systemy przetwarzania obrazów, Rozdział w pracy zbiorowej „Nowoczesna Technika w Kulturze, Nauce i Oświacie - komputery, audio, video, TVSat, multimedia, infostrady", WOK Tarnów, 1995.

[37] Tadeusiewicz R., Mikrut Z.: Pattern Recognition Using Neural Networks, Proc. of the 8-th International Conference „SystemModeling-Control”, vol. 3 „Artificial Neural Networks and their Applications", Łódź, 1995.

[38] Tadeusiewicz R.: Sieci neuronowe w przetwarzaniu i rozpoznawaniu obrazów, Seminarium „Komputerowa analiza obrazu w technologii żywności", ART, Olsztyn, 1994.

[39] Tadeusiewicz R.: Finding of Optimal Structure of the Neural Network for Image Processing and Pattern Recognition, Invited Session on Neural Networks for Signal Processing, IEEE Signal Processing Symposium, Warszawa, 1996.

[40] Tadeusiewicz R.: Optyczne czytniki (I), Magazyn Komputerowy ENTER, nr 6, 1992.

[41] Tadeusiewicz R.: Optyczne czytniki (II), Magazyn Komputerowy ENTER, $\mathrm{nr}$ 7, 1992.

[42] Mikrut Z.: Estimation of the hidden layer size based on analysis of neural networks for handwritten digit recognition, Appl. Math. and Comp. Sci., vol. 4, no. 3, 1994.

[43] Gorgoń M., Mikrut Z., Tadeusiewicz R.: Image Processing Systems at Biocybernetic Lab of AGH: from TTL to Modern FPGA. In: Colnaric M., Adamski M., Węgrzyn M.: Real-Time Programming, IFAC Publications, Elsevier, 2003.

[44] Gorgoń M., Wiatr K., Mikrut Z., Tadeusiewicz R.: Rekonfigurowalne architektury systemów sprzętowych do przetwarzania i analizy obrazów w pracach AGH, Elektronizacja - podzespoły i zastosowania elektroniki, nr 7-8, 2003.

[45] Tadeusiewicz R., Gorgoń M., Wiatr K., Mikrut Z.: Reconfigurable Image Processing Architectures - Research and Current State of Art at the AGH Technical University, in: Plaks T. P., Athanas P.M. (eds.): Proceedings of the International Conference on Engineering of Reconfigurable Systems and Algorithms ERSA'02, Las Vegas, 2002.

[46] Gorgoń M., Tadeusiewicz R.: Hardware Based Image Processing Library for Virtex FPGA, in Schewel J., Athans P.M., Dick Ch.H., McHenry J.T.: Reconfigurable Technology - FPGAs for Computing and Applications II, Proceedings of SPIE, vol. 4212, Boston, 2000.

[47] Tadeusiewicz R., Korohoda P.: Komputerowa analiza i przetwarzanie obrazów, Wydawnictwo Fundacji Postępu Telekomunikacji, Kraków, 1997. 